\title{
Persona, Comunidad y Bien Común
}

\author{
Por el R. P. FELIPE MC GREGOR. S. J.
}

Una antigua y veneranda costumbre cristiana ponía y pone en las puertas de las ciudades, en los dinteles de las casas la efigie o la advocación del santo o ángel tutelar a cuyo especial cuidado están encomendadas.

Es una costumbre no siempre plenamente comprendida, pero cuyo significado es a la vez una expresión de fe, una dedicación y una petición esperanzada.

En el liminar de esta Semana Social, recinto ideológico que nos congrega, han querido sus organizadores poner primero el nombre santo de Dios y la alabanza de su grandeza en el sacrificio con que la comunidad cristiana recuerda y renueva la oblación y el sacrificio del Verbo de Dios encarnado; y luego, como guías tutelares, dos ricas ideas cristianas: la de persona y la de comunidad.

Expresamos así nuestra profunda adhesión intelectual a las exigencias que el reconocimiento de ambas ideas impone.

En el debate sordo o estridente de las ideas individualistas o colectivistas y de las sociedades e instituciones nacidas del colectivismo o del individualismo, exageraciones de la persona o de la comunidad, manifestamos cúál es nuestra dedicación: pretendemos establecer el armonioso conjunto de ambos en una auténtica prosecución del bien común.

$Y$ al inspirar en el bien común nuestros ideales para la reconstrucción del mundo y de la porción que está más cerca de nuestro corazón y de nuestro cuidado, nuestra Patria el Perú, estamos seguros de servir las más nobles, las más altas, las más osadas de las exigencias que pueden concebirse, (excluídas tan solo las utopías) para el establecimiento de un nuevo orden social, más justo, más humano, más cristiono.

¿Por qué, señores? Porque la persona es la manifestación del espíritu que hace aparecer en el mundo el pensamiento, el amor, la elección, la entrega, la comunión, es decir: lo más noble y sublime que el mundo conoce.

Porque la comunidad es la común unión de personas que aumentan en su mutuo don y perpetúan su riqueza individual. El lenguaje, la cultura, la historia, la vocación común de los pueblos, la empresa común de tra- 
bajar la naturaleza y ponerla al servicio del hombre, son floraciones magníficas del necesario y maravilloso don del hombre al hombre en la comunidad.

Entremos, pues, guiados por las exigencias intelectuales de las nociones de persona y comunidad, $\alpha$ ver cómo se conjugan en el bien común.

$\mathrm{El}$ bien es el objeto del deseo. Bueno es lo que todos deseamos. Bien y bueno son apelativas más amplios que los objetos materiales. Lo que el hombre desea no son sólo las cosas que se pueden contar, medir o pesar. Todo lo que de algún modo existe tiene precisamente ese mismo modo de bien.

Común $\alpha$ un grupo humano es lo que a todos pertenece en la diversidad de maneras que la pertenencia presenta. Común es por ejemplo a una familia un patrimonio o herencia ${ }_{n}$ por pertenencia $\mathrm{y}$ exigencia jurídica; común es a un grupo racial determinada cualidad biológica, el pelo ensortijado de los negros o el ojo rasgado del amarillo, por pertenencia y necesidad biológica común es a una nación el éxito en los azares de una guerra; por pertenencia y exigencia moral; común es a todos los hombres la razón o la voluntad, por exigencia metafísica del ser específico a que pertenecen.

Lo que es común comprende potencialmente a cada una de las partes. $Y$ las partes son tanto más necesarias para la unidad cuanto tienen menos de pedazo y más de "miembros".

No hay unidad más profunda en el dominio de la naturaleza sensible que la unidad del viviente; y el viviente cuanto más vida tiene, cuanto más elevado esté en la categoría de los vivientes, más diferenciado en sus partes y más unido a ellas hasta necesitarlas y depender de ellas.

No es una la cristalización salina o el grano de arena sino con una mera unidad de agregación; rompiéndolos o fragmentándolos se tienen nuevos cristales 0 nuevos granos de arena, solo diversos entre sí por el tamaño ¿será posible fragmentar así el organismo vivo del ser humano?.

La asociación moral de los hombres que se agrupan para una empresa común ofrece también este dato misterioso de una diversidad mayor en relación estrecha con la unión y necesidad mútua. ¡Cuanto más diversos más unidos!

Y cuando se considera la entrega y amor mútuo que florece en la unión conyugal se entrevé muy pronto cómo ella es más grande cuando las personas siendo diversas se complementan.

El bien, pues, de la unión es diverso del bien de las partes; no es una mera suma o agregación de ellas ni lo que a cada uno separado podría convenir.

La vida organizada señala en su estructura un dato más de ricas enseñanzas: las partes unidas entre sí, forman el todo; no es la agregación de la mano hecha directamente al corazón que la irriga y la renueva, ni al cerebro que la mueve y la coordina sino al brazo y al tronco y por la mediación de éstos al corazón o al cerebro. La unión de funciones reclama precisamente la diferencia de partes, que la vida junta para complementorlas.

En el ser social esto significa la necesaria diferenciación y agrupa- 
ción en familias, comunidades naturales, asociaciones profesionales, clanes o grupos diversos por la función que en el ser social realizan.

Hay más: el bien de la unión en la comunidad de los seres vivos no es estático sino esencialmente dinámico. Este dinamismo busca sus ráíces en la entraña de la vida; se afianza en lo vivido - lo que llaman pasadopara de allí proyectarse hacia el futuro, expandirse y ampliarse.

El bien de los seres vivos es crecimiento, es desarrollo y progreso. El bien de la común unión de los seres vivos ho puede consistir en formas fijas; medidas estáticamente equilibradas, inmutabilidad semejante a lo inanimado.

$Y$ como los bienes son tan diversos, la común unión de las personas y su agrupación en familias, comunidades naturales, instituciones, es tan rica y tan variada, su equilibrio, dinámico y progresivo, resulta sumamente difícil definir o describir con alguna precisión lo que es el bien común.

En una descripción redactada por un grupo de teólogos, alerta no sólo a las exigencias de la verdad abstracta sino a su expresión y condicionamiento histórico, el bien común de un ser social se presenta como:

"un conjunto dinámico organizado, armónico y jerarquizado, de riquezas, servicios, condiciones generales, situaciones, proyectos $Y$ planes que interesan a un grupo de personas y a cada una do las que lo componen en cuanto la persona forma parte del grupo".

Interesa ir desentreñando el contenido de esta descripción para repensar juntos cuáles son los bienes, cómo se unen entre sí y cómo se ordenan en esa realidad socio moral que llamamos bien común.

Pero interesa además aplicar ese contenido a nuestra Patria. El bien común del Perú en diferencia del de Brasil o Bolivia.

Lo forman primero, riquezas materiales, en toda la extensión que la palabra tiene sobre todo entre los economistas. El suelo, subsuelo, el mar, el trabajo del hombre convertido en industrioso empeño y permanente instrumento de dominio material de una naturaleza bravía y altiva, feraz y yerma, que mantiene diálogo constante con el mar en la inmensidad movediza de sus costas, con el cielo en la altura imperturbable de sus montes y con el profundo, en la galería subterránea de sus minas o en los depósitos oscuros de su petróleo.

Pero es riqueza también y de más subido precio, la experiencia histórica de mezclar razas, fundir y modelar culturas unificando las creencias religiosas y la conciencia común hasta expresarlas en un lenguaje, hasta tejer las hebras de un nuevo y poderoso lazo que ha unido y unirá más entre sí a todos los peruanos.

Y esta vida en común reclama y establece servicios no sólo materiales como el transporte postal de nuestros mensajes o el registro de nuestros estados o nuestro bienes, o el cuidado de la salud de nuestros hombres y la salubridad del territorio: sino sociales como el de vigilancia y policía de la vida y propiedad privada o común, o los más importantes como son la educación, el régimen jurídico de propiedad $\mathrm{y}$ trabajo, el orden político que hace posible la vida ciudadana. 
Y como la vida singular tiene una atmósfera, un clima en que debe desarrollarse y sin en el que muere por asfixia, así el vivir común reclama como condición indispensable una condición general de libertad, un respeto a la auténtica definición del hombre en sus ideas y sus obras y sobre todo una amistad sincera que reconociendo las diferencias permita la colaboración cívica eficazmente creadora.

El bien común es históricamente condicionado -no es el mismo en la encrucijada peligrosa que vive el Perú hoy que fué en las primeras décadas posteriores a la independencia o cuando hace cien años se vivía lo que Basadre ha llamado el renacimiento liberal y la contra ofensiva conservadora.

Por eso es tan importante el reflexionar en común, dialogar sobre la incidencia de la coyuntura histćrica en el bien común de la Patria para que las orientaciones para las "personas y corporaciones privadas" como para la acción en la vida cívica tengan esa autenticidad $\mathrm{y}$ oportunidad que la gravedad del momento reclama.

Pero más importante aún que la visión de un momento o el auscultar del ritmo de la vida colectiva en una determinada fase hislórica es la conciencia en cada una de las partes de pertenecer a un todo. El bien común reclama la conciencia de un destino común. Destino es proyección hacia el futuro y el futuro para los que tenemos fe en Dios y en la libertad del hombre no está escrito, ni es trágicamente necesario sino que es el resultado de nuestro honrado y generoso esfuerzo y de su gracia que nunca falta.

La pasiva consideración del sucederse de los hechos, la morbosa delectación en el comentario de lo mal que se sucede o la veleidosa elucu. bración de cómo deberían sucederse, no construye. Quien así mira los sucesos, las posibilidades o los riesgos de la Patria, no siente su vinculación a ella como parte de su destino, ni siente el destino, el futuro de la Patria como resultado de su esfuerzo.

Y este dinámico ordenamiento de bienes, servicios, condiciones generales, voluntad común y fidelidad al presente, sólo puede hacerse cuando hay jerarquía en el orden y armonía en el movimiento.

Traiciona el bien común quien, por atender $a$ un bien pasajero $\circ$ inferior, sacrifica un bien estable o superior. Lo que los economistas nos repiten frecuentemente sobre el espejismo y falsedad de la inflación que atiende la necesidad de hoy y multiplica por cien las de mañana, es nada más que un incidente y una aplicación a algo muy secundario en el bien común, de la ley general que venimos exponiendo. ¿El orden cívico de policía y de fuerza puede acaso justificar de modo ordinario el sacrificio de la libertad? La falta de instituciones ciudadanas o de conciencia cívica que vivimos: ¿no es un resultado del sacrificio repetidamente renovado en nuestra historia del orden político y de la libertad individual?

Hagamos por fin referencia a la necesidad de armonía en el desarrollo del bien común. Armonía es proporción de partes, que cuando son sonoras forman las melodías. Parte son del bien común, las riquezas, los servicios, las condiciones generales, pero parte en un sentido mucho más hondo y mós real son los hombres para quienes esos bienes existen. 
Bueno es lo que todos desean y bien es el objeto del deseo, ¿no fueron éstas acaso nuestras posiciones iniciales cuando juntos empezamos hace unos momentos esta indagación acerca de lo que es el bien común?. Naturalmente el bien del Perú es deseado por los peruanos. Y sin ellos no existirían esos bienes parciales que lo integran.

El crmino que nos queda aquí por recorrer es entonces ton inmensamente lurgo, cuanto es urgente. La desarmonía, el desequilibrio humano entre el indígena de la serranía y el hombre de la ciudad es inmensa.

Repitámoslo, la armonía, la proporción de las partes, necesarias para el bien común, reclama que $\alpha$ todos llegue, para todos sean y todos contribuyan al acerbo común de las riquezas, servicios, condiciones generales que forman el bien común.

Con razón pues se considera como la máxima expresión del bien común la paz definida por ese noble, grande y santo apóstol de la paz que fué Su Santidad Pío XII, como:

"la tranquilidad en el orden fundado por la unión de los espíritus en la misma verdad $y$ en la misma caridad; este orden influye ante todo en las inteligencias y los corazones $\mathrm{y}$ se ejercita en colaboración armónica de obras en todos los campos de la vida sin excluir el político... social y económico". (Pío XII - Radiomensaje de Navidad de 1934).

Es clara la profunda interacción de causas y efecto que existe entre el bien común y la paz social y es manifiesta la nobleza, la altura, la grandeza y la dignidad del bien común que este somero análisis presenta.

Las diversas exposiciones que los hombres han hecho en el decurso del tiempo para tratar de explicar la naturaleza del ser social, han todas encontrado la necesidad de referirse al bien común como gozne o punto cardinal de su explicación.

Lo llaman con nombres muy variados, bien del Estado, bien de la ciudad, interés general, razón de estado, interés público, progreso, etc.

Le dieron una función a veces desorbitada, por ejemplo, en el pensamiento político antiguo, renacido en el maquiavelismo moderno, que hacía del bien del Estado un absoluto que condiciona aún la misma moralidad individual.

Citar esas varias opiniones nos alejaría de nuestro tema alargando la exposición. Quiero tan solo referirme de paso a la doctrina de Santo Tomás de Aquino nuevamente descubierta por los pensadores y políticos.

Santo Tomás sha construído una coherente ciencia del Hacer moral, individual y del quehacer social, que constituye la Política, centrándoias ambas en torno a la idea del bien común.

De él son estas frases cuya claridad de contenido irrumpe aún a través de los tecnicismos con que son expresadas.

"Non est aliqua virtus cujus actus non sit ordinabilis ad bonum commune vel mediate vel inmediate". (1.2๙c. q.96 a.3 ad 3 um.) 
Y esta otra mucho mós expresiva aún:

"Non est autem recta voluntas alicuius hominis volentis aliquod bonum particulare, nise referat illud in bonum commune sicut in finem". (1. 2ac. q. 19 a. 10. c.)

Al describirlas funciones más importantes del ejercicio de la actividad política, gobernar, legislar, juzgor, Santo Tomás recurre constantemente al bien común como medida ideal, norma y fin de esas acciones.

Al que tiene oficio de administrar justicia en la comunidad humana entrega Santo Tomás el bien común que coincide con la justicia: "non iudex habet curam boni communis quod est justitia".

Al que legisla se le pone también como medida el bien común (1. 2ac. qs.96 y 97) para que con su actividad "ordenadora" "commune bonum justitice et pacis conservent" (1. 2ac. q.96 a. 3. c.)

Colocándolo en la perspectiva de estas enseñanzas se comprende el problema teórico de la primacía del bien común sobre el bien individual. Si el bien común tiene esta austera grandeza, esta sobria exigencia, este inmenso valor, resulta claramente comprensible que se le anteponga al bien de los individuos y si en estos no hay una dimensión trascendente $\alpha$ su destino meramente temporal esta subordinación es justa. Por eso, sólo cuando la luz de la revelación alumbró haciendo lúcida la dignidad y el valor de lo persona humana, el estudio de las relaciones entre el bien común $y$ el bien individual pudo plantearse en sus verdaderos términos.

La síntesis de ambos no está acabada; ni es estática y uniforme, sino algo eminentemente dinámico y vital.

Hay un bien de la persona - la persona misma- que no puede jamás ponerse en la caiegoría de medio para conseguir aún el máximo beneficio para el bien común. Y la persona estó constituída por su interioridad, su razón y su conciencia, su libre albedrío y la ordenación a un bien trascendente que se expande y perfecciona en la vocación sobrenatural. Estos constitutios de la persona se separan de la acepción común de bienes particulares, pues forman la singularidad o individualidad que distingue a cada hombre y lo prolonga más allá del tiempo en el que la sociedad tiene su realización y su límite.

Los otros bienes de la persona, los que son realmente bienes particulares, sí están sujetos a una comparación, una medida, o una jerarquía que es la del bien común.

El comité teológico de Lyon cuya descripción del bien común nos ha servido de hilo conductor en la exposición de hoy, ha precisado también las relaciones entre el bien común y los bienes particulares:

"Por razón de su importancia $y$ de su dignidad, el bien común de la sociedad civil sobrepasa y prima, por consiguiente, sobre los bienes particulares de las personas y aún de los grupos subordinados, por numerosos y poderosos que sean".

Si una persona o un grupo acupara en su provecho el bien que debería ser común, la sociedad se encuentra en ese estado violento que los antiguos llamaban tiranía; si el poder no logra 
procurar el bien común por encima de los intereses individuales. o de grupos, la sociedad se encuentra en el estado desordenado llamado anorquía".

uede haber tiranias o anarquías larvadas que pasan inadvertidas por el gran público; no son por eso menos peligrosas. Algunos pueblos pueden complacerse en la tiranía o la anarquía, como ciertos enfermos experimentan complacencia mórbida en su mal; no por eso están menos enfermos. Lo que no quiere decir, sin embargo, que entre el bien común $y$ los bienes privados sea natural y necesaria la oposición. Lo natural es la armonía, con las justas subodinaciones que supone".

"Por una parte, en efecto, el bien común es el de una sociedad humana. No podría ser sino humano, con el orden de razón y de justicia implicado en esa palabra. El bien común, si constituye, como lo hemos indicado, un fin, no es, sin embargo, el fin único y supremo; se ordena el bien propiamente personal, es decir, espiritual de las personas, a su expansión humana en el tiempo $y$ en la eternidad. No hay oposición de suyo entre el verdadero bien común y el verdadero bien personal. La oposición se produce sólo en caso de falsa concepción del bien común, o del bien personal, o de esos dos bienes a la vez, como en el conflicto entro el individualismo, noción errónea del bien personal, y el socialismo, noción errónea del bien común. Por otra parte, un orden humano de justicia exige que el todo social de ninguna manera absorba, como el "Leviathan", de Hobbes, las partes que lo componen, sino, al contrario, que las respete, en su singularidad viviente. De ahi que toda injusticia evitable, que aflije durablemente a uno de los grupos integrados por el pueblo, aunque sea de poca importancia numérica, aparece como contraria a la esencia misma del bien común; no podría ser aceptada sino como un mal menor temporario y con la voluntad de ponerle fin lo antes posible. Pues el bien común no el de una mayoría del pueblo, menos todavía de unạ minoría, por importante que sea, sino del pueblo entero".

"Finalmente, el bien privado de una persona o de un grupo puede, de una cjerta manera $y$ sin perder su carácter privado, entrar en el bien común de la sociedad civil, incluso de la comunidad humana. La ciencia de un Pasteur, la santidad de un Vicente de Paul eran sus bienes propios; no menos forman parte del patrimonio francés y del patrimonio humano. Esta observación concierne, sobre todo, a los bienes del espíritu, que la división no destruye, sino, al contrario, aumenta por la difusión".

"Entre el bien común y el bien particular, la oposición no proviene de la naturaleza de las cosas, sino de la contingencia, que se opone a la perfección, y más a menudo del pecado, de las avari: cias, concupiscencias, orgullos, envidias, odios que oscurecen las inteligencias y falsean la conducta de los ciudadanos $y$ de sus gobernantes". 
Hay una última y muy urgente consideración que hacer en la común reflexión acerca del bien común que hemos emprendido:

La definición o descripción precisa del bien del individuo y su relación con las riquezas, los servicios, la condición general-de un ser social puede dejar de lado o no presentar con la debida claridad el más importanto de los elementos del bien común, es a saber la común unidad de ese bien.

En un magistral mensaje de Navidad describió Pío XII, en 1954, la profunda diferencia que existe entre la coexistencia y la paz. Me váis $\alpha$ permitir alguna extensión en la cita para que el pensamiento del santo $Y$ sabio Pontífice quede lucidamente expuesto: Se duele el Pontífice que la humanidad sacudida $y$ aterida por tantos $y$ graves dolores nueve años después de la guerra no encuentre el camino de la paz $\mathrm{y}$, en vez de la sinceridad, cordialidad y claridad de la paz verdadera, tan solo experi. mente el plomizo e indefinido estado de temor que se ha dado en llamar: "paz fría":

"La paz fría es tan solo una calma provisional, cuya duración depende de la sensación mudable del temor y del cálculo oscilante de las fuerzas presentes, mientras que no tiene nada del orden justo que supone una serie de relaciones convergentes hacia un fin común, justo y recto".

"Es impresión sacada, de la simple observación de los hechos, que el principal fundamento en que se apoya el estado presente de calma relativa es el temor. Cada uno de los grupos en que se halla dividida la familia humana tolera que exista el otro porque el mismo no quiere perecer. Evitando de este modo el riesgo fatal, ambos grupos no conviven sino coexisten. No es un estado de guerra, pero tampoco es paz, es una calma fría. $A$ cada uno de los grupos acucia el temor del poder militar y económico del otro. En ambos se halla vivo el recelo por los efectos catastróficos de las armas novísimas".

"Con angustiosa atención sigue cada uno el desarrollo técnico de los armamentos del otro y su capacidad de producción económica, mientras confía a la propia propaganda el papel de sacar partido del temor ajeno, reforzando y exagerando su alcance. En el terreno concreto de la política parece que, arrebatados los hombres después de tantas desilusiones por un colapso extremo del escepticismo, no cuentan ya sobre otros principios morales o racionales".

Abandonados los principios racionales o morales, la imposibilidad práctica de los hombres para juntos contribuir al bien común de la humanidad, nace de que tan solo coexisten en el error $y$ en el temor.

Trágico sería poder afirmar que una comunidad nacional, la comunidad peruana, por ejemplo, no tiene vida común sino que en ella los grupos coexisten, en el temor o en el error.

Por eso es igualmente antisocial y anticristiano el movimiento que pretende aumentar en las clases o grupos sociales el resentimiento y el te- 
mor mútuo como el que pretende causar o quizás conservar el error acerca de castas, privilegios, doctrinas económicas o políticas.

En la gravedad sombría de la hora es deber de conciencia de todo peruano contribuir al bien común de nuestra Patria disipando el temor que nace del desconocimiento, del recelo, de, la inferioridad sentida o la superrioridad creída.

Es igualmente imperativo oponerse a la propaganda de odio y divi. sión, venga de quien viniere.

Pero eso no basta: no podemps coexistir en el error. Sorprende y desalienta ver el tremendo desconocimiento económico, político, social que tenemos y que parece como si quisiéramos continuar teniéndolo.

$Y$ no estoy yo muy cierto que ese error es inculpable. No podría yo afirmar con convicción y certeza que hemos hecho no lo suficiente, pues claramente no lo ha sido, sino aún lo necesario para conocer y señalar la verdad de nuestro auténtico bien común.

Por eso este esfuerzo de la Primera Semana Social tiene significación y oportunidad tan grande, como ella la tienen todos los esfuerzos que hoy se hacen para despertar y acrecentar la conciencia cívica nacional.

Llegado casi al final de esta reflexión, en voz alta y compartida con vosotros, acerca de la naturcleza del bien común debo añadir algunas notas más para esbozar las inmensas perspectivas que la luz de la fe abre ampliando la riqueza de este tema.

San Pablo habló en una ocasión de un olivo silvestre $\underline{y}$ estéril en el que se injertó un retoño de olivo nuevo y fértil y dijo: esa es la imagen del Israel según la carne y el Israel de Dios. El olivo nuevo es Cristo.

Anólogamente podemos decir ahora: en el pié de acodo de una sociedad meramente terrenal injertó Cristo su Iglesia, sociedad espiritual, viña mística de la que El es na solo la savia sino el fruto más preciado.

Su Iglesia la comparó El también por su apóstol Pablo a un cuerpo en el que Cristo es el principio vital que influye en los miembros, les comunica su influjo vital, procura el crecimiento de su cuerpo dotándolo de las funciones necesarias y sosteniendo estas funciones en su ejercicio.

De Cristo procede la unidad estrecha e indestructible en la diversidad de todas las partes, de todos los miembros de la Iglesia.

"Pues a la manera que el cuerpo es uno y tiene muchos miembros Y todos los miembros del cuerpo con ser muchos constituyen un solo cuerpo, así también Cristo".

"Por que en un mismo espíritu todos nosotros fuimos bautizados, ya judíos, ya griegos, ya esclavos, ya libres en razón de formar un solo cuerpo... Y si padece un miembro juntamente padecen todos los miembros y si se goza un miembro juntamente se gozan todos los miembros".

"Y vosotros sois cuerpo de Cristo y miembros cada uno por su parte. (I Cor. XII, 12, 13, 17).

Cuando los seguidores del Señor formularon para nuestra enseñanza rel resumen de nuestra fe nos enseñaron a decir "Creo en la comunión de 
Ios Santos" lo que equivale a decir, afirmo con la seguridad que me presta el testimonio de Dios en la íntima y profunda dependencia de los hombres, su virtud beneficia a los demás, aumenta en ellos la vida de gracia, su pecado influye en los demás, disminuye el vigor vital del cuerpo místico de Cristo.

¿Puede concebirse mayor bien común que el que así nos describe el dogma de la comunión de los Santos? ¿ Comprendemos mejor ahora porqué toda la ley se resume en amar a Dios sobre todas las cosas y al prójimo como a nosotros mismos? Y Jesús nos enseñó con palabras y ejemplo que es amor.

Pero hay más, aún la salvación personal, la realización plena de la vocación sobrenatural de cada uno de nosotros sólo puede lograrse en el seno de la Iglesia santa, es decir tiene un signo y sentido social, reclama la inserción en la vid mística, la pertenencia al Cuerpo Místico del Señor.

De modo anólogo y basándonos en los mismos principios podemos concluir, la lección principal que esta Semana pretende exponer se resume así:

A procurar el bien común nos obliga además de nuestra dignidad de hombres la más fundamental exigencia de nuestra fe cristiana.

El bien común del Perú en un sentido muy auténtico es el mayor bien da cada uno de los peruanos. 